\title{
Correlation between Serum Interleukin-31 Level and the Severity of Atopic Dermatitis in Children
}

\author{
Rabie Bedir Atallah ${ }^{1}$, Ahmed Wahhed-Allah Amer ${ }^{1}$, Hesham Samir Abd El-Samee², Reham \\ Mahmoud Ibraheem ${ }^{3}$ \\ Departmentsof ${ }^{1}$ Dermatology, Venereology \&Andrology and ${ }^{2}$ Clinical pathology, New Damietta \\ Faculty of Medicine, Al-Azhar University, Damietta, ${ }^{3}$ Departments of Dermatology, Desouk General \\ Hospital, Egypt \\ Corresponding author: Reham Mahmoud Ibraheem, Mobile: 01005156262; Email: reham19885@gmail.com
}

\begin{abstract}
Background: Atopic dermatitis (AD) is a chronic inflammatory skin disease, characterized by intense itch, typical localization and a specific image of skin lesions. Pathogenesis of pruritus in AD is not fully understood, but recent studies emphasize the role of interleukin-31 (IL-31). This relatively recently described cytokine is considered to be a potential mediator inducing pruritus in AD.
\end{abstract}

Aim of the Work: was to assess the correlation of serum IL-31 level and the disease severity in children with AD.

Patients and Methods: a case control study. Sera were obtained from 50 AD children and 30 healthy volunteers. IL-31 levels were measured using ELISA with standard kits from EIAab R\&D Systems. Serum IL-31 levels were correlated with AD disease activity. Disease severity in children with AD was assessed using the SCORAD (Severity scoringof atopic dermatitis) index.

Results: Serum IL-31 level was significantly higher in AD children (Mean \pm SD 99.73 \pm 75.93 ) than in healthy children (Mean \pm SD $54.01 \pm 57.36$ ), (p-value $=0.019)$. Serum IL-31 levels correlated positively with the calculated severity score (SCORAD index), $\left(r_{s}=0.480\right.$, $p$ - value $\left.<0.001\right)$

Conclusion: The results of this study confirm the importance of IL-31 in AD pathophysiology. Serum IL-31 level is an objective reliable marker of AD severity in children. It may represent a novel target for antipruritic drug development.

Keywords: atopic dermatitis, interleukin-31, severity SCORAD, pruritus, children.

\section{INTRODUCTION}

Atopic dermatitis (AD) is a chronic, relapsing and pruritic inflammatory skin disease, characterized by typical localization and a specific image of skin lesions, with coexistence of other atopic diseases. Diagnostic criteria for AD elaborated by Hanifinand Rajka have been universally accepted, due to a large variety of the clinical picture ${ }^{[1]}$. Pruritus is one of the most common symptoms in $\mathrm{AD}$, practically occurring in each patient. Therefore, it has been included as one of the four major diagnostic criteria ${ }^{[1,2]}$. Scoring the intensity of pruritus is an integral part of the SCORAD (Severity SCORing of Atopic Dermatitis) index, which is commonly used to determine the severity of the disease ${ }^{[3]}$. The etiology of pruritus in AD is not fully explained, however the participation of some endogenous mediators, neurotransmitters, arachidonic derivatives and cytokines has been taken into consideration in itch pathophysiology ${ }^{[4]}$. Recently, in numerous studies, interleukin-31 (IL-31) has been associated with the pathogenesis of pruritus in chronic inflammatory skin diseases ${ }^{[5]}$. This relatively newly described cytokine is preferentially produced by activated $\mathrm{T}$ cells skewed towards $\mathrm{Th} 2{ }^{[6]}$. Interleukin-31 is related to the IL- 6 cytokine family ${ }^{[7]}$. It signals through a heterodimeric receptor composed of IL-31 receptor $\alpha$ (IL-31RA) also known as gp130-like receptor (GPL) and oncostatin M receptor (OSMR) ${ }^{[6,8,9]}$. Other studies revealed that IL-31 serum levels are higher in patients with $\mathrm{AD}$ comparing to healthy controls ${ }^{[10]}$. Moreover, serum IL-31 levels correlate with the disease activity in atopic patients ${ }^{[11]}$.

Evidence of the importance of IL-31 in the pathogenesis of pruritus is also present in studies on IL-31 inhibitors relevant to the treatment of $\mathrm{AD}^{[12,13]}$.

The aim of the study was to assess the correlation between serum IL-31 levels and severity of $\mathrm{AD}$ in children.

\section{PATIENTS AND METHODS}

This study included a total of 80 subjects, divided into two groups; group I: 50 patients with atopic dermatitis and group II: 30 Healthy volunteers served as control group. They were 
attending at Out-patient Clinic of Dermatology \&Venereology Department; Al-Azhar University Hospital, Damietta and Desouk General Hospital. Approval of the ethical committee and a written informed consent from all the subject parents were obtained. This study was conducted between January 2018 to August 2018.

Venous blood samples were obtained from patients and control subjects. Serum IL-31 was measured using ELISA technique with standard kits from EIAab R\&D Systems. Sera were stored at $-30^{\circ} \mathrm{C}$ until assayed. All analyses were performed according to the manufacturer's protocol. Disease severity was determined using the SCORAD (Severity scoring of atopic dermatitis) index including subjective symptoms, extent and intensity of the lesions.

\section{STATISTICAL ANALYSIS}

Data were collected, summarized and reported on data collection sheets. Data was re-entered into computer Microsoft Excel sheets with appropriate tabulation and graphical presentation. Data entry, processing and statistical analysis was carried out using MedCalc ver. 15.8. Tests of significance (Chi square, student's t-test, Mann-Whitney's test,
Spearman's correlation coefficient and multivariate linear regression analysis) were used. Data were presented and suitable analysis was done according to the type of data (parametric and non-parametric) obtained for each variable. P-values less than $0.05(5 \%)$ was considered to be statistically significant.

\section{RESULTS}

Group I: 50 patients with atopic dermatitis; their ages ranged between 3 and 11 years [mean \pm standard deviation $(\mathrm{SD})=5.98 \pm 2.35$ years] . They comprised 30 boys $(60 \%)$ and 20 girls (40\%). Group II: 30 Healthy volunteers served as control group. This group comprised healthy children without past, current or family history of allergic disorders. Their ages ranged between 3 and 10 years [mean \pm standard deviation (SD) $=6.50 \pm 2.39$ years $]$. They comprised 20 boys (66.7\%) and 10 girls (33.3\%).

\section{Serum IL-31 levels in both groups}

Table 1 shows the median and quartile values of serum IL-31 level in both groups. We found significant differences between the group of patients with $\mathrm{AD}$ and $\mathrm{CG}$ (Figure 1).

The statistical analysis showed that serum IL31 level was significantly higher in AD than in the control group ( $\mathrm{AD}$ vs. $\mathrm{CG}, \mathrm{P} \leq 0.05)$.

Table (1): Comparison between the two studied groups regarding serum levels of IL31.

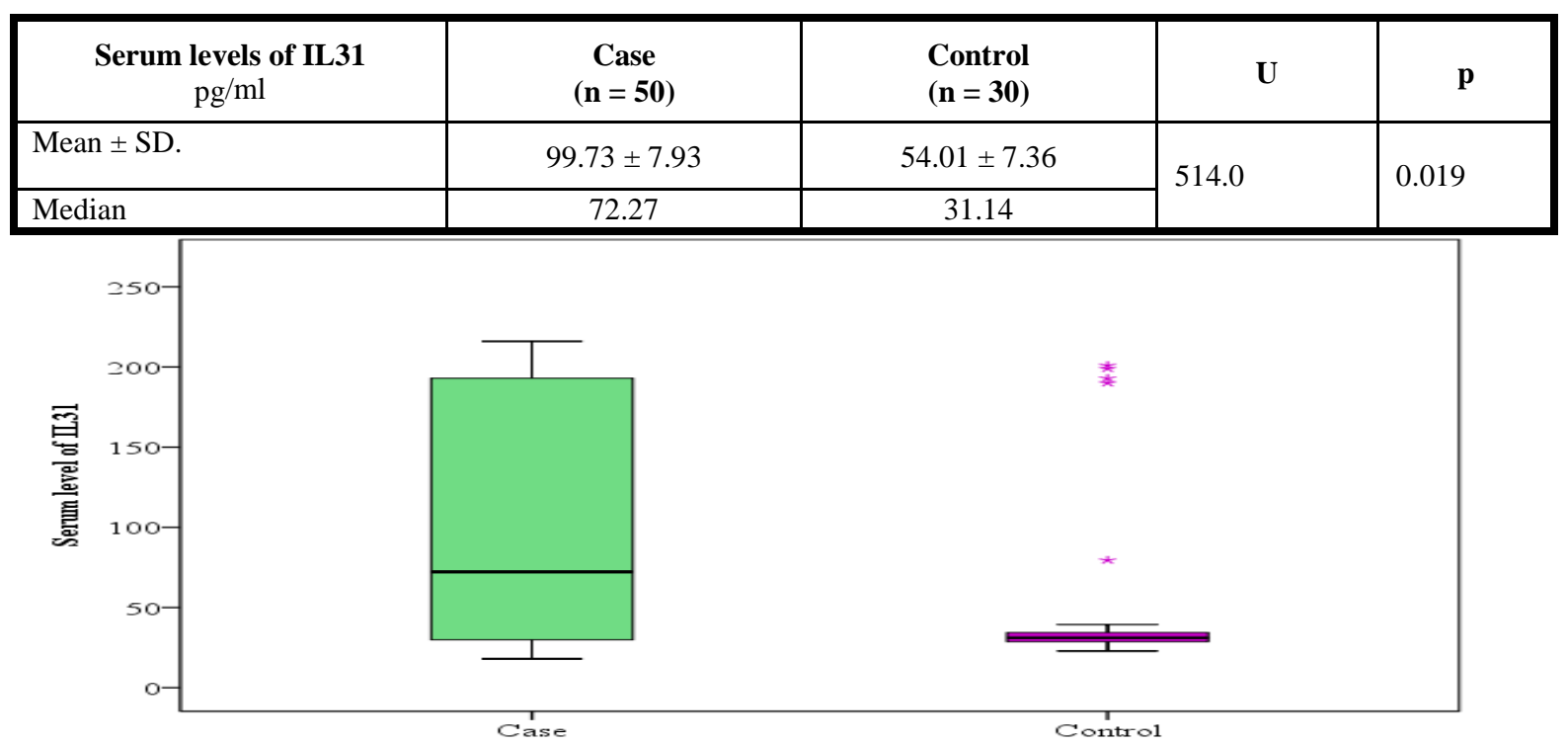

Figure (1): Comparison between the two studied groups regarding serum levels of IL31.

Correlation between serum IL-31 level and the disease severity

Serum IL-31 level correlated with the disease severity by SCORAD index $(p<0.001)$. table (2)

The serum level of IL-31 was highly significant in correlation to the SCORAD score among the study group $(\mathrm{P}<0.005)$. (Figure2)

Table (2): Correlation between serum levels of IL31 and SCORAD score in atopic group. 


\begin{tabular}{|l|l|l|}
\hline & $\mathbf{r}_{\mathrm{s}}$ & $\mathbf{p}$ \\
\hline SCORAD score & 0.480 & $<0.001$ \\
\hline
\end{tabular}

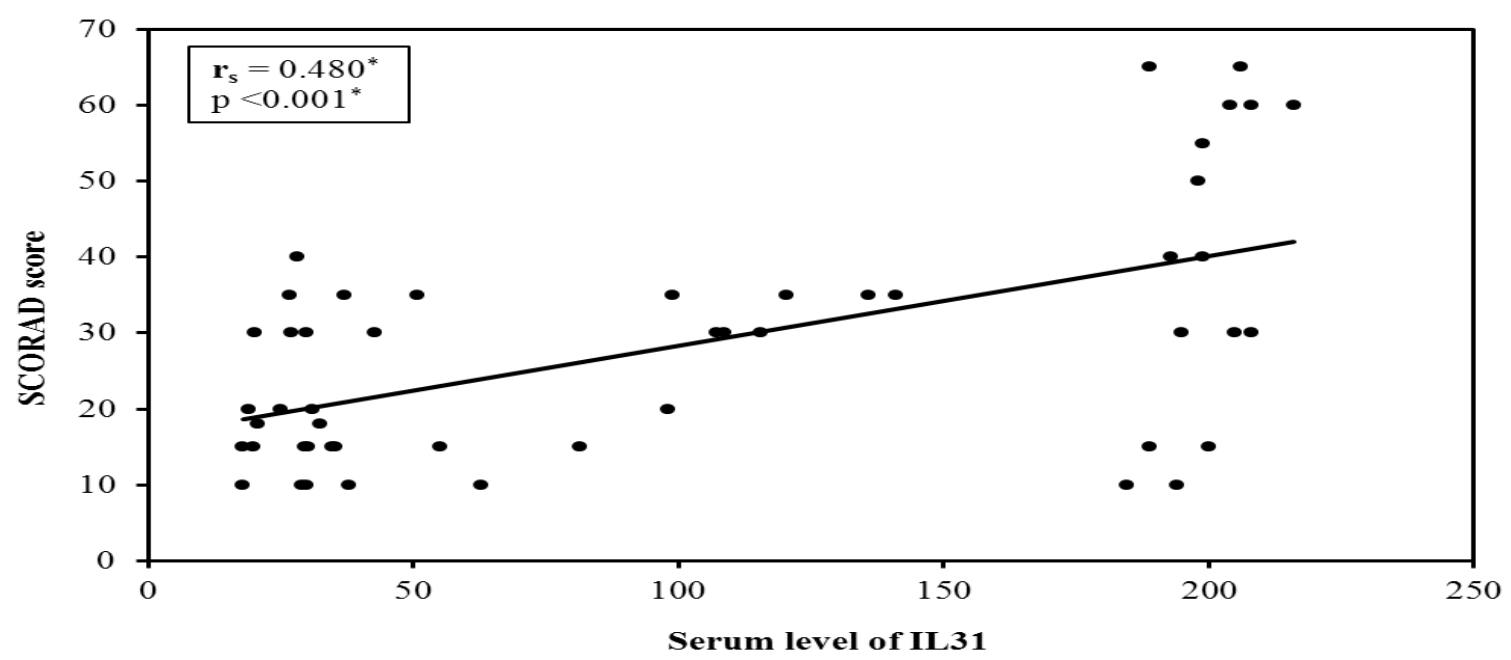

Figure (2): Correlation between serum levels of IL31 and SCORAD score in atopic group.

Table 3 shows the relation between the severity of atopic dermatitis according to the SCORAD index and the serum level of IL31 showed significant correlation between mild and moderate cases and between moderate and severe cases where $(\mathrm{P}<0.05)$. While the correlation was highly significant when comparing mild and severe cases $(\mathrm{P}<0.005)$. (Figure 3$)$.

Table (3): Relation between severity according to SCORAD index and serum level of IL31 in atopic group.

\begin{tabular}{|l|c|c|c|c|c|}
\hline \begin{tabular}{c} 
Serum level of $\begin{array}{c}\text { IL31 } \\
\mathrm{pg} / \mathrm{ml}\end{array}$ \\
\cline { 2 - 4 }
\end{tabular} & $\begin{array}{c}\text { Mild } \\
(\mathbf{n = 2 3})\end{array}$ & $\begin{array}{c}\text { Moderate } \\
(\mathbf{n = 2 0})\end{array}$ & $\begin{array}{c}\text { Severe } \\
(\mathbf{n = 7})\end{array}$ & \multirow{2}{*}{$\mathbf{H}$} & $\mathbf{p}$ \\
\hline Mean \pm SD. & $64.18 \pm 6.18$ & $104.53 \pm 8.94$ & $202.85 \pm 8.57$ & & \\
\hline Median & 32.56 & 108.05 & 204.0 & & \\
\hline Sig.bet.Grps & \multicolumn{2}{|c|}{$\mathrm{p}_{1}=0.048, \mathrm{p}_{2}<0.001, \mathrm{p}_{3}=0.007$} & 17.544 & $<0.001$ \\
\hline
\end{tabular}




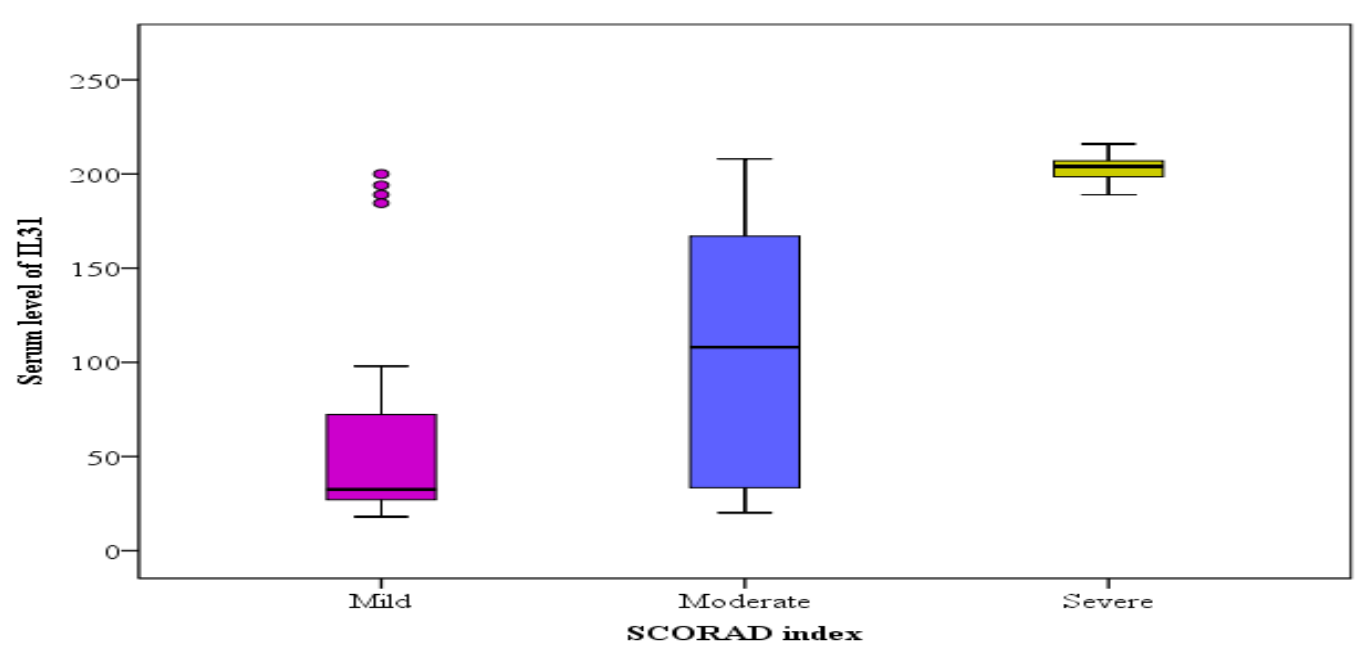

Figure (3): Relation between severity according to SCORAD index and serum level of IL31 in atopic group.

\section{DISCUSSION}

Atopic dermatitis (AD) is a chronic, relapsing and pruritic inflammatory skin disease, characterized by typical localization and a specific image of skin lesions, with coexistence of other atopic diseases. Pruritus is one of the most common symptoms in $\mathrm{AD}$, practically occurring in each patient ${ }^{[14]}$. Scoring the intensity of pruritus is an integral part of the SCORAD (Severity Scoring of Atopic Dermatitis) index, which is commonly used to determine the severity of $\mathrm{AD}^{[3]}$. During the last few years, the involvement of novel interleukins, as IL-31, emerged ${ }^{[15]}$. IL-31 is a cytokine that is believed to play an important role in atopic dermatitis (AD). IL-31 levels positively correlate with disease severity in children with $\mathrm{AD}^{[16]}$. IL-31 is a novel Th2-cellderived cytokine that induces severe pruritus and dermatitis, and is increased in AD skin lesions. In several studies, IL-31 serum levels in $\mathrm{AD}$ correlate with disease severity [17]. Recently, interleukin-31 (IL-31) has been associated with the pathogenesis of pruritus in chronic inflammatory skin diseases. This relatively newly described cytokine is preferentially produced by activated $\mathrm{T}$ cells skewed towards Th2 [5]. We held a crosssectional comparative study and enrolled 50 patients with atopic dermatitis and 30 healthy volunteers as control group, with ages ranging between 3 to 12 years old to assess the correlation between serum IL-31 levels and the disease severity in patients with $\mathrm{AD}$. We found that serum interleukin-31 was significantly high among the cases with $\mathrm{AD}(\mathrm{P} \leq 0.05)$. This comes in agreement with all previous studies, where, Raap et al., as one of the first, achieved significantly higher serum IL-31 levels in the group of patients with AD ${ }^{[11]}$. Similar results were obtained by Ezzat $\boldsymbol{e t}$ al. and Kim $\boldsymbol{e t}$ al. comparing serum IL-31 levels in AD patients with healthy ones. Analysis of serum IL-31 levels were performed in both cases using ELISA method, obtaining significantly higher results in $\mathrm{AD}$ patients ${ }^{[18,19]}$.

Nobbe et al. demonstrated increased immunoreactivity of IL-31 in infiltrating inflammatory cells in $\mathrm{AD}$ compared with pruritic or Th2-mediated diseases ${ }^{[10]}$.

Szegediet al. proved that T cells in chronic AD skin produce IL-31 and that AD lesions contain increased levels of these IL-31-producing $\mathrm{T}$ cells ${ }^{[20]}$. Cornelissen et $\boldsymbol{a l}$. found enhanced expression of the gene that encodes the cytokine IL-31 in skin lesions of patients with $\mathrm{AD}^{[21]}$.

Amin and their colleges in their study, reported that there was a significant increase of IL-31 expression in patients with $\mathrm{AD}$ at sites of the lesions when compared with the nearby apparently normal skin of the same patients ${ }^{[22]}$. In our study we proved a correlation between the serum level of IL-31 and the severity of AD, where the serum level of IL31 was highly significant in correlation to the SCORAD score among the study group $(\mathrm{P}<0.005)$, where the relation between the severity of atopic dermatitis according to the SCORAD index and the serum level of IL31 showed significant correlation between mild and moderate cases and between moderate and severe cases where $(\mathrm{P}<0.05)$. While the correlation was highly 
significant when comparing mild and severe cases $(\mathrm{P}<0.005)$. This comes in line with the results of Ezzat et al. who showed a show a positive correlation between the severity of the disease and serum IL-31 levels ${ }^{[18]}$.

Kim et al. also pointed out to a positive correlation and a strong interrelation between serum levels of IL-31, the degree of the disease severity and mRNA level for this cytokine in skin biopsies of patients with $\mathrm{AD}^{[19]}$.

Amin and their colleges in their study, also reported similar results to ours, where they stated that there was a statistically significant positive correlation between the intensity of IL31 expression in patients with $\mathrm{AD}$ regarding SASSAD score reflecting AD severity [22].

This result agreed with Lei et al., who found that IL-31 expression was positively correlated with severity of $\mathrm{AD}{ }^{[23]}$. On the contrary, Siniewicz-Luzeńczyk et al., found different results from those, where they found no correlation between the severity of the disease and serum IL-31 levels ${ }^{[14]}$, which may be partly consistent with Neisset al.'s study, who found statistically increased mRNA levels of IL-31 in biopsy specimens of patients with $\mathrm{AD}$, irrespective of the disease severity ${ }^{[24]}$.

\section{CONCLUSION}

It could be concluded that the serum IL-31 level is shown to be higher in children with $\mathrm{AD}$ than in healthy patients, which is consistent with the results given by other researchers and is significantly correlated to the severity of the disease. The results of this study confirm the importance of IL-31 in AD pathophysiology. Serum IL-31 level is an objective reliable marker of $\mathrm{AD}$ severity in children. It may represent a novel target for antipruritic drug development.

Conflict of interest: No financial and personal relationships between authors and others that might be perceived by others as biasing their work. Potential conflicts do not exist.

\section{REFERENCES}

1. Hanifin JM, Rajka G (1980): Diagnostic features of atopic dermatitis. ActaDermatolVenereol (Stockh), 92:44-7.

2. Hanifin JM, Thurston M, Omoto M et al. (1994): The eczema area and severity index (EASI): assessment of reliability in atopic dermatitis. EASI Evaluator Group. ExpDermatol., 10: 11-8.
3. European Task Force on Atopic Dermatitis (1993): Severity scoring of atopic dermatitis: the SCORAD index. Dermatology, 186: 23-31.

4. Stander S, Steinhoff M (2002): Pathophysiology of pruritus in atopic dermatitis: an overview. ExpDermatol., 11: 1224.

5. Castellani ML, Salini V, Frydas $\mathrm{S}$ et al. (2006): Interleukin-31: A new cytokine involved in inflammation of the skin. Int $\mathrm{J}$ ImmunopatholPharmacol., 19: 1-4.

6. Heinrich PC, Behrmann I, Haan S et al. (2003): Principles of interleukin (IL)-6-type cytokine signalling and its regulation. Biochem J., 374: 1-20.

7. Dillon SR, Sprecher C, Hammond Aet al. (2004):Intreleukin 31, a cytokine produced by activated $\mathrm{T}$ cells, induces dermatitis in mice. Nat Immunol., 5: 752-60.

8. Ghilardi N, Li J, Hongo JA et al. (2002): A novel type I cytokine receptor is expressed on monocytes, signals proliferation, and activates STAT-3 and STAT-5. J Biol Chem., 277: 16831-6.

9. Yamaoka K, Okayama Y, Kaminuma O et al. (2009): Proteomic approach to Fcepsilon RI aggregation-initiated signal transduction cascade in human mast cells. Int Arch Allergy Immunol., 149: 73-6.

10. Nobbe $S$, Dziunycz $P$, Mühleisen $B$ et al. (2012): IL-31 expression by inflammatory cells is preferentially elevated in atopic dermatitis. ActaDermVenereol., 92: 24-8.

11. Raap U, Wichmann $\mathrm{K}$, Bruder $\mathrm{M}$ et al. (2008): Correlation of IL-31serum levels with severity of atopic dermatitis. J Allergy ClinImmunol., 122: 421-3.

12. Metz S, Naeth G, Heinrich PC et al.(2008): Novel inhibitors for murine and human leukemia inhibitory factor based on fused soluble receptors. J Biol Chem., 283: 5985-95.

13. Venereau E, Diveu C, Grimaud $\mathrm{L}$ et al. (2010): Definition and characterization of an inhibitor for interleukin-31. J Biol Chem., 285: 14955-63.

14. Siniewicz-Luzeńczyk K, StańczykPrzyłuska A, Zeman K (2017): Correlation between serum interleukin-31 level and the severity of disease in children with atopic dermatitis. Advances in Dermatology and Allergology/PostẹpyDermatologii

Alergologii, 30(5), 282-285. 
15. Di Salvo E, Ventura-Spagnolo E, Casciaro M et al. (2018): A Potential Inflammatory Pathway," Mediators of Inflammation, 18 (3858032): 8.

16. Marsella $R$, Ahrens $K$, Sanford $R$ (2018): Investigation of the correlation of serum IL-31 with severity of dermatitis in an experimental model of canine atopic dermatitis using beagle dogs. Vet Dermatol., 29(1):69e28.

17. Cheon BR, Shin JE, Kim YJ et al. (2015): Relationship between serum 25hydroxyvitamin D and interleukin-31 levels, and the severity of atopic dermatitis in children. Korean Journal of Pediatrics, 58(3): 96-101.

18. Ezzat MH, Hasan ZE, Shaheen KY (2011): Serum measurement of interleukin-31 (IL-31) in paediatric atopic dermatitis: elevated levels correlate with severity scoring. J EurAcadDermatolVenereol., 25:334-9.

19. Kim S, Kim HJ, Yang HS et al. (2011): IL-31 serum protein and tissue mRNA levels in patients with atopic dermatitis. Ann Dermatol., 23:468-73.

20. Szegedi K, Kremer AE, Kezic S et al. (2012): Increased frequencies of IL-31producing $\mathrm{T}$ cells are found in chronic atopic dermatitis skin. ExpDermatol., 21:431-6.

21. Cornelissen $\mathbf{C}$, Lüscher-Firzlaff $\mathbf{J}$, Baron JM et al. (2012): Signaling by IL-31 and functional consequences. Eur J Cell Biol., 91:552-566.

22. Amin TE, Elfar NN, Sallam FA (2018): Immunohistochemical study of interleukin-31 in patients with atopic dermatitis. Egypt J DermatolVenerol., 38:5964.
23. Lei $\mathrm{Z}$, Liu G, Huang Q et al. (2008): SCF and IL-31 rather than IL-17 and BAFF are potential indicators in patients with allergic asthma. Allergy, 63:327-332.

24. Neiss MM, Peters B, Dreuw A et al. (2006): Enhanced expression levels of IL-31 correlate with IL-4 and IL-13 in atopic and allergic contact dermatitis. J Allergy ClinImmunol., 118:930-7. 